\title{
Discussion on the Mechanism of Internet Finance Promoting the Development of Technology Finance
}

Deyu Chen

Guangzhou College of Commerce, Guangzhou 510000, Guangdong, China. E-mail: chendeyu666@163.com

Fund Project: This article is the quality project of the Provincial Education Department, the Practice Teaching Base for College Students Project: The Comprehensive Practice Teaching Base for finance of Guangzhou Business School (presided by Chen Deyu) stage results: Topic number: 2018sjxsjwsjjjjdjy01

Abstract: Internet finance can effectively solve the problem of scientific and technological financial information asymmetry, identify financial risks, and provide new ideas for the innovation and development of financial technology mechanisms. Based on this, this article starts with the problems existing in the development of my country's science and technology finance, and proposes a method of applying Internet finance to promote the development of science and technology finance for reference. Keywords: Internet Finance; Technology Finance; Development Mechanism

Technological finance is a financial tool for technological development and promotion of the upgrading and transformation of high-tech industries. With the rapid development of Internet finance nowadays, technology finance has also shown a new trend, which has become a key issue for people in the financial industry. Now, in the Internet financial environment, how to promote technological and financial innovation through the Internet is a key issue for technological and financial breakthroughs, and plays a very important role in solving the institutional problems.

\section{Problems in the development of science and technology finance in my country}

\subsection{Information asymmetry among technology investment and financing entities}

The asymmetry and imperfection of information among the subjects of technology investment and financing will hinder the innovation and development of technology and finance to a certain extent. From an essential perspective, most technology companies have different degrees of information asymmetry and incompleteness from the beginning of their operations to the development stage, and this feature will inevitably cause information asymmetry with financial institutions. On the one hand, due to their own development characteristics, technology companies cannot disclose complete information, which makes it more difficult for financial institutions to evaluate their development capabilities. This makes it difficult for technology companies to obtain sufficient financial support and cannot do business with companies. On the other hand, financial institutions have the problem of opaque information. Many technology companies cannot obtain accurate financial loan information in the first time, and thus cannot make loans ${ }^{[1]}$.

\subsection{Problems in the identification and control of technological finance risks}

From the perspective of technology finance itself, there is a high risk, which is also one of the difficulties hindering its development. One aspect is technical risk. For most technology companies, all aspects such as technological development or 
business operation models are unstable, and in various stages of development, the instability factors in technology companies will also change, bringing risks and The manifestations are also different, and financing needs will also be very different. In view of these unstable factors, it is very difficult for technology finance to conduct risk assessment. This is also the difference between technology finance and traditional finance. On the other hand, the risks are caused by information asymmetry. The emergence of scientific and technological financial risks is directly related to information asymmetry. The scientific and technological innovation projects themselves are relatively professional, and the technological prospects cannot be accurately predicted. The asymmetry of information between the development of the project and the investment subjects make the project construction required funds. It could not get timely follow-up. If the market lacks an effective solution to the problem of information asymmetry, it will trigger financial risks.

\subsection{The technology financial service system is not yet perfect}

Judging from the current situation, the science and technology financial service system is still faced with problems such as imperfect capital market development, scientific resource allocation, and insufficient institutional mechanisms. This is specifically reflected in: First, the capital market is not sound. According to relevant investigations and studies, my country's financing scale is relatively small, and most of the technology projects are invested indirectly through banks. At present, my country's market entry barriers are relatively high, which is still out of reach for most of the technology companies in the early stages of development ${ }^{[2]}$. Second, the financing difficulties and high costs for technology companies. For most technology companies, the current assets available in the early stages of development are limited, the corresponding financial and accounting systems are not perfect, the property rights are not clear, and there is no standard system for good evaluation of technology companies. Large investment risks directly lead to the difficulty of financing technology companies. Even if some companies can obtain a certain amount of financing, they cannot meet actual needs. The existence of these problems makes it impossible for most technology to apply for loans in a timely manner ${ }^{[3]}$. Third, there is a shortage of professional technology financial service personnel. The science and technology projects completed by science and technology companies have high technical content and are cutting-edge features. Financial service personnel can adapt to their jobs only if they have the corresponding skill level, so that they can identify and control risks more scientifically. However, most financial institutions now lack professional high-quality talents who understand both the Internet and the technology and finance, which affect financial services.

\section{Analysis of the mechanism of Internet finance to promote the development of technology finance}

\subsection{Internet financial interactive platform solves the problem of asymmetry of scientific and technological financial information}

The emergence of Internet finance has provided a complete information exchange platform for both investment and financing parties, and updated the methods of information collection, analysis, and application.

First, Internet finance has broadened the channels for technology finance to obtain information. Under the traditional financial system, the product production and financing of technology companies will be affected by the market environment and cannot apply for loans from banks in time. On the Internet financial platform, through information interaction, a lot of data traces, such as customer feedback, will be stored. Using big data model analysis, the platform can identify and judge, so that the financing of technology companies can proceed smoothly.

Second, Internet finance can reduce the cost of technology and financial information. Generally speaking, compared with other small and medium-sized enterprises, technology companies have many unstable market factors, risks, and insufficient risk tolerance. The financing characteristics of technology companies in each Jiedu Pill are also different. Under the Internet financial system, technology companies can directly conduct transactions with investors online, which can broaden financing channels, and is a more typical P2P model. In this mode, a large number of investors and financing can be attracted in a short period of time. At the same time, it can also analyze massive data and information, collect customer information, and the new cost is lower ${ }^{[4]}$.

Third, Internet finance can increase the transparency of technology finance. The mechanism formed under the Internet 
finance model is transparent and is a mechanism that can ensure the scientific nature of the allocation of financial funds. Under this financial model, the method of connection between the supply and demand of funds has changed, so that both parties can more efficiently connect. At the same time, the increase in transparency has also attracted a large amount of social capital to be integrated into science and technology projects.

\subsection{Relying on big data to promote the establishment of risk assessment and control mechanisms for technology finance}

In the big data environment, whoever has the most data can occupy a favorable market position. Big data is one of the important tools for financial sales, and it is also one of the important means to assess and control risks. Under the Internet financial system, the use of "cloud computing ideas to process data and make data more standardized. Financial institutions can use these data to analyze and effectively control risks. For example, platforms such as Alipay integrate customer data, including transactions, behaviors, etc. Data is integrated, a data model is constructed, and verified by a third party to identify customers and prevent and control risks. In addition, in the Internet finance model, a financial supplier can issue loans to multiple demanders at the same time, and can be operated in batches. Risk diversification. Especially in the innovation of credit investigation mechanism, because some small technology companies have limited information sources, the traditional credit investigation mechanism is not relevant, and the enterprise credit situation cannot be accurately reflected, while the application of big data is basically zero Cost, with the help of massive data, the overall operating status of the enterprise can be reflected.

\subsection{Promote a high degree of integration between Internet technology and key financial services}

In fact, Internet finance is the integration of Internet technology and financial services. Technological financial services in the Internet environment must run through the entire process of technological innovation and promote the construction of a multi-level and multi-angle technological financial system.

First, the Internet has prompted financial institutions to use various effective methods to provide services to customers, such as providing risk investors with corresponding financial risk solutions.

Second, Internet finance can provide technology companies with differentiated services based on various development stages. For the initial stage of enterprise development and entrepreneurship, the venture capital generated is generally a matter of obtaining funding from relatives, friends and other parties, and various forms of accelerated service products can be set up. For example, you can find investors who can make venture capital through multiple channels, and help clients start stock valuation work. For the problem that customers mainly rely on venture capital financing in the later stages of enterprise development, Internet technology can be used to formulate comprehensive financing solutions.

\section{Conclusion}

All in all, the emergence of Internet finance has effectively solved the problem of information asymmetry in science and technology finance, which relying on big data to promote the establishment of risk assessment and control mechanisms for science and technology finance, and at the same time promote a high degree of integration between Internet technology and key financial businesses. Therefore, we must recognize the advantages of Internet finance to better serve the development of technology finance.

\section{References}

1. Hu GL, Chen T. Research on the development of science and technology finance under internet finance. Contemporary Economy 2017; 2(12): 128-135.

2. Cui. Research on technology finance innovation and development mechanism based on internet finance framework. Lanzhou Journal 2018; 12(03): 432-447.

3. Ding Y. Internet finance development model and its supervision mechanism analysis. Financial Theory and Practice 2018; 3(02): 322-325.

4. Zhou M. Research on the financing mode of internet finance for small and micro enterprises. Global Market 2017; 2(05): 402-409. 